DOI: http://dx.doi.org/10.22484/2177-5788.2017v43n2p327-335

\title{
$O$ radiojornalismo como ferramenta de divulgação científica
}

\author{
Luciano Victor Barros Maluly
}

Resumo: O artigo analisa a produção de programas radiojornalísticos cujo objetivo é a divulgação científica. São objetos do estudo os especiais Cremilda Medina e o Ato Presencial, Mara Ferreira Rovida e o Jornalismo em Trânsito e Felipe Simão Pontes e a Teoria do Jornalismo de Adelmo Genro Filho, transmitidos pela Rádio USP entre o final de 2016 e o início do ano de 2017 durante o programa Universidade 93,7. Propõe-se discutir formatos determinados de produção radiofônica que, por meio do planejamento, podem facilitar a compreensão de pesquisas acadêmicas, especialmente aquelas voltadas ao campo da comunicação.

Palavras-Chave: Divulgação científica. Radiojornalismo. Rádio USP.

\section{Radio Journalism as a scientific divulgation tool}

Abstract: The paper analyzes the production of radio news programs whose purpose is the scientific divulgation. The objects of study were the special programs Cremilda Medina e o Ato Presencial, Mara Ferreira Rovida e o Jornalismo em Trânsito e Felipe Simão Pontes e a Teoria do Jornalismo de Adelmo Genro Filho, broadcast by USP Radio during the 93,7 University program by the end of 2016 and beginning of 2017. It is proposed to discuss specific formats of radio journalism production that through planning, may facilitate the understanding of academic research, particularly those aimed to the Communication field.

Keywords: Scientific divulgation. Radio journalism. Radio USP. 


\section{Introdução}

Muitos pesquisadores têm seus trabalhos prestigiados no universo acadêmico, mas o conhecimento pouco chega à população, ficando limitado aos especialistas. É neste universo, que a divulgação científica, segundo Bueno (2009) ${ }^{1}$ presta um serviço de utilidade pública, com o radiojornalismo caracterizando-se como uma das ferramentas de auxílio aos cientistas que, em parceria com os comunicadores, facilitam o entendimento das pesquisas produzidas nas diversas áreas.

A Rádio USP ${ }^{2}$ opera desde 11 de outubro de 1977, com uma programação diversificada, que veicula programas musicais, jornalísticos, autorais, entre outros. A divulgação científica está incluída na grade da emissora que, assim, oferece um espaço para os pesquisadores. Um desses programas surgiu em 2008, por meio de uma parceria com o Departamento de Jornalismo e Editoração da Escola de Comunicações e Artes da Universidade de São Paulo.

Os alunos do departamento produziam programas radiojornalísticos que eram, apenas, disponibilizados na internet. Foi assim que surgiu, por iniciativa dos estudantes, a ideia de entrar em contato com a Superintendência de Comunicação Social (SCS), setor que administra as mídias da instituição. A solicitação era simples, ou seja, reivindicar um horário na programação da rádio. A emissora aceitou imediatamente o desafio e o programa Universidade 93,7 (nome escolhido pelos alunos) continua sendo transmitido aos domingos, entre onze horas e meio-dia.

Os formatos apresentados variam conforme a pauta, com a produção de programas opinativos, radiojornais, entrevistas (debate, mesa-redonda etc.), especiais e autorais. Neste último caso, os alunos ficam livres e com a possibilidade de planejar novos produtos como radiorrevistas, temáticos, entre outros. As matérias, especialmente as reportagens, estão presentes na maioria dos programas.

Os programas são gravados no Laboratório de Radiojornalismo João Walter Sampaio Smolka, do CJE, sendo que a duração média é de trinta minutos. O departamento também disponibiliza um $\operatorname{site}^{3}$, que tem a função de repositório dos programas. Assim, além de ouvir o

1 O professor e pesquisador da Universidade Metodista de São Paulo, Wilson da Costa Bueno compreende a divulgação científica como "[...] a utilização de recursos, técnicas, processos e produtos (veículos ou canais) para a veiculação de informações científicas, tecnologias ou associadas a inovações ao público leigo." (BUENO, 2009, p. 162).

2 Informações sobre a Rádio USP estão no Portal do Jornal da USP, 2017. Disponível em: <http://jornal.usp.br/radio/>. Acesso em: 9 abr. 2017.

3 Radiojornalismo. Programa Universidade 93,7. Disponível em: 〈http://www.usp.br/cje/radiojornalismo/>. Acesso em: 9 abr. 2017. 
conteúdo, os interessados podem fazer download dos arquivos. Outras informações, como vídeos, fotos, pesquisas, bibliografias, planejamento do projeto, ficha técnica e demais dados sobre o Universidade 93,7, também estão disponíveis.

Um das propostas do projeto da USP é a veiculação de programas voltados à divulgação de pesquisas científicas, com destaque para as áreas da Comunicação, especialmente o Jornalismo. As pautas originam-se quando o assunto merece destaque, ou mesmo quando pesquisadores desejam divulgar seus trabalhos.

Os Especiais, como serão discutidos neste artigo, revelam o radiojornalismo como uma ferramenta, principalmente para os pesquisadores da área que têm interesse em apresentar e discutir os resultados de trabalhos científicos desenvolvidos nas universidades. Serão analisados, por este âmbito, três programas que foram transmitidos pelo Universidade 93,7.

Os produtos radiofônicos relacionam o autor e a pesquisa e foram conduzidos por jornalistas científicos, termo utilizado aqui para os produtores e mediadores dos programas, no caso Jorge Kanehide Ijuim, Marcelo Cardoso e Marcelo Engel Bronosky, respectivamente responsáveis pelos programas Cremilda Medina e o Ato Presencial, Mara Ferreira Rovida e o Jornalismo em Trânsito e Felipe Simão Pontes e o Segredo da Pirâmide de Adelmo Genro Filho.

\section{Cremilda Medina e o Ato Presencial}

O livro, Ato presencial, mistério e transformação, publicado em 2016, é fruto das pesquisas de Cremilda Celeste de Araújo Medina, professora sênior do Departamento de Jornalismo e Editoração da Escola de Comunicações e Artes da Universidade de São Paulo (ECA/USP). Medina é considerada uma das principais referências em jornalismo, tendo publicado obras como A arte de tecer o presente: narrativa e cotidiano, em 2003, e Notícia, um produto à venda, em 1978. A publicação apresenta relatos da autora, assim como inclui trabalhos de colaboradores, principalmente orientandos e parceiros nas produções acadêmicas, como destaca o professor e pesquisador da Universidade Federal de Santa Catarina, Jorge Kanehide Ijuim:

Como lhe é peculiar, Cremilda sempre procura trazer à suas obras um caráter polifônico. Em Ato presencial, registra depoimentos de ex-alunos, parceiros de jornadas e entrevistados que enriquecem e fundamentam seus argumentos em defesa do contato humano. Estes revelam sensibilidade solidária, sintonias geracionais, confluências entre ideias e pessoas de sua caminhada. (IJUIM, 2017, p. 190-191).

O programa Cremilda Medina e o Ato Presencial foi planejado para situar o leitor diante da vida e da obra da autora, tendo - como pano de fundo - o lançamento do livro. Ex-aluno e admirador do pensamento da pesquisadora sobre jornalismo e comunicação, Ijuim foi também 
o responsável pela condução do programa. O professor destaca a experiência como locutor e produtor:

Participar do planejamento e produção do programa Cremilda Medina e o Ato presencial foi uma experiência exitosa. Além do privilégio de ter acesso em primeira mão ao livro-tema do programa, foi necessário revisitar vida e obra da autora, o que proporcionou um momento extraordinário de aprendizado e esclarecimento. A culminância do projeto foi a gravação do programa que marcou um diálogo de Cremilda de forma rica e enriquecedora. (IJUIM, 2017).

A admiração que o entrevistador tem pela autora foi revelada durante a gravação do programa. A segurança foi mútua, observada no diálogo descontraído, cujo principal objetivo foi a transmissão da mensagem ao público, ou melhor, de sua extensão, como observa Cremilda Celeste de Araújo Medina:

\footnotetext{
Sempre é gratificante para um autor repercutir o seu trabalho com entrevistas e publicações, porque há uma expansão dessa produção ao público em geral. Agora, esse caso foi uma experiência ainda mais satisfatória, na medida em que os produtores estavam muito bem informados sobre esse trabalho, porque são parceiros e compreendem perfeitamente a trajetória das obras, das pesquisas e dos grupos dentro da universidade. A interlocução foi importante, porque se manteve um diálogo fluido, pleno e rico em trocas, sem ser uma entrevista formal, em que se faz uma pergunta e se responde friamente sobre o conceito que a pergunta já traz em si. (MEDINA, 2017).
}

De acordo com o planejamento do roteiro foram introduzidos dois depoimentos (de um colega de trabalho e de uma orientanda) e três peças radiofônicas, sendo dois trechos do livro e uma resenha (lidas por dois colaboradores, um professor e uma aluna), além de músicas escolhidas pela entrevistada. O programa foi gravado no dia 28 de novembro de 2016, ao meiodia, sendo transmitido em duas edições pela Rádio USP, respectivamente nos dias 8 e 15 de janeiro de 2017, sempre às 11 horas.

\section{Mara Ferreira Rovida e o Jornalismo em Trânsito}

O livro Jornalismo em Trânsito: o diálogo social solidário no espaço urbano (2015), de Mara Ferreira Rovida, é fruto da tese de doutorado da pesquisadora defendida no Programa de Pós-Graduação em Ciências da Comunicação da ECA/USP, em 2014. A obra mereceu destaque na mídia em $2016^{4}$, quando foi classificada como uma das finalistas do $58^{\circ}$ Prêmio Jabuti, na categoria Comunicação. Pelo fato de o trabalho ser fruto de pesquisas desenvolvidas na instituição, nada melhor do que uma entrevista com autora e, por isso, Rovida destaca a potencialidade do rádio diante da divulgação científica:

\footnotetext{
${ }^{4}$ Portal do $58^{\circ}$ Prêmio Jabuti. 2016. Disponível em: <http://premiojabuti.com.br/finalistas-2016/todas-categorias4/>. Acesso em: 9 abr. 2017.
} 
A entrevista foi mais do que um momento de divulgação do trabalho que fiz. Foi especial porque voltei à minha escola, ao lugar onde a pesquisa foi desenvolvida. Além disso, compartilhei o estúdio de rádio, um lugar que me é muito caro, com duas pessoas que fizeram parte da minha trajetória, dois professores que encontrei ao longo da minha formação. [...] Num sentido mais prático e menos sentimental, acredito que o espaço de discussão da produção científica precisa ser valorizado. O que produzimos de conhecimento no mundo acadêmico ainda parece ficar dentro dos muros da universidade e é justamente a possibilidade de ir além dessas barreiras que o programa apresenta. (ROVIDA, 2017).

A conversa foi mediada pelo jornalista e pesquisador Marcelo Cardoso, que destaca, na mesma lógica de Mara Ferreira Rovida, o aspecto educativo de programas veiculados em emissoras ligadas às instituições de ensino e pesquisa.

\begin{abstract}
A importância do programa está na divulgação científica de produção editorial fruto de pesquisas, neste caso, da Universidade de São Paulo. A abordagem da temática principal tem certo imediatismo se comparada ao conteúdo veiculado por emissoras comerciais. Cumpriu-se a função educativa dessa rádio universitária. (CARDOSO, 2017).
\end{abstract}

Cardoso foi professor da autora, posteriormente colega de classe e hoje acompanha suas pesquisas. Em resenha publicada sobre o livro na Revista Regit, ele ressalta um dos principais pontos da obra, quando a autora aproxima os trabalhos dos jornalistas e dos personagens, como no caso dos caminhoneiros:

Foi inevitável surgirem paralelos entre os trabalhos dos repórteres, que dirigem os veículos da emissora de rádio, e os motoristas de caminhão. A análise da autora é que as condições de precariedade dos trabalhos de ambos encontram-se no mesmo espaço, as ruas e as rodovias. A terceirização, a perda de direitos trabalhistas e as inúmeras horas no trânsito fazem parte de um cenário onde jornalistas, cada vez mais, preferem (ou são obrigados) a se transformar em pessoas jurídicas. (CARDOSO, 2016, p. 140).

O programa seguiu um esquema com a introdução de dois trechos das obras, que foram interpretados por uma colaboradora externa, a professora Lenize Villaça, da Universidade Presbiteriana Mackenzie, além das músicas, que foram escolhidas pela entrevistada. O programa foi gravado no dia 16 de novembro de 2016, às 15 horas, sendo transmitido no dia 4 de dezembro de 2016, às 11 horas, pela Rádio USP.

\title{
Felipe Simão Pontes e o Segredo da Pirâmide de Adelmo Genro Filho
}

O livro Adelmo Genro Filho e a Teoria do Jornalismo (2015) é fruto das pesquisas realizadas durante o doutorado de Felipe Simão Pontes, cuja tese foi defendida no Programa de Sociologia Política da Universidade Federal de Santa Catarina no mesmo ano da publicação. No ano seguinte, o livro também foi finalista do $58^{\circ}$ Prêmio Jabuti na categoria Comunicação. A publicação de Pontes criou um impacto no universo da comunicação ao analisar uma das principais e mais polêmicas obras da área no Brasil. Além disso, o livro trouxe uma reflexão 
em torno dos atuais problemas do jornalismo, como destaca a professora e pesquisadora da Universidade Estadual de Ponta Grossa (UEPG), Cintia Xavier (2017, p. 186):

\begin{abstract}
As várias entradas que Adelmo Genro Filho e a teoria do jornalismo oferece vão além da contribuição para a teoria do jornalismo. É possível ter boas doses de reflexão a respeito da ética profissional e compreender melhor os caminhos da organização profissional. $\mathrm{O}$ percurso histórico adotado também contribui para a reflexão dos desafios profissionais. Nesse aspecto, ao reconstituir os anos 1980 nas redações brasileiras, faz entender como o diploma para o exercício do jornalismo deixou de ser obrigatório em junho de 2009.
\end{abstract}

Felipe Simão Pontes também é professor e pesquisador da UEPG, sendo um dos principais estudiosos da teoria do jornalismo na atualidade. Ao destacar a relevância de propostas que atendem ao princípio de circulação nacional do conhecimento em jornalismo, como no caso da entrevista transmitida pela Rádio USP, o autor revela uma forma de aproximação do público diante de questões pesquisadas nesse campo.

\begin{abstract}
Na entrevista, tive a oportunidade de tratar sobre a vida de Adelmo Genro Filho, sobre a teoria do jornalismo proposta por ele em $\mathrm{O}$ Segredo da Pirâmide: para uma teoria marxista do jornalismo; sobre as diferentes recepções deste livro no campo jornalístico e sobre a atualidade de algumas de suas proposições. Também houve a oportunidade de indicar alguns aspectos do reconhecimento de minha tese, transformada em livro e indicada à premiação do Prêmio Jabuti (na categoria Comunicação). [...] Expor meu trabalho e o pensamento de Genro Filho para a comunidade da Universidade de São Paulo e, em particular, no Departamento de Jornalismo e Editoração da Escola de Comunicações e Artes, atende ao princípio de circulação nacional do conhecimento sobre o jornalismo, com a oportunidade da crítica qualificada que os ouvintes do programa podem dirigir ao livro. Nesse aspecto, avalio como muito positivo esse programa, e agradeço o espaço para minha participação. (PONTES, 2017).
\end{abstract}

O mediador da entrevista foi o pesquisador e também professor do curso de graduação e do Mestrado em Jornalismo da UEPG, Marcelo Engel Bronosky, colega de Felipe Pontes na mesma instituição. O professor destaca a iniciativa de parcerias que observem a divulgação científica, especialmente no campo do jornalismo.

Quando provocado a realizar entrevista com o colega Felipe Pontes a respeito do resultado de sua pesquisa sobre Adelmo Genro para o rádio, me pareceu uma ideia original, pois não é comum encontrar no meio rádio assuntos desta natureza sendo discutidos. De pronto aceitei o desafio. Além disso, essa proposta oferece possibilidade de intensificar parcerias com outras instituições do campo do jornalismo no Brasil para além das relações de pesquisa. [...] Para a realização da entrevista utilizamos um dos estúdios de radiojornalismo do curso da UEPG. Conduzido por um conjunto de perguntas que procurassem representar a complexidade do assunto, mesclado com informações a respeito da indicação da obra para o prêmio Jabuti [...]. A respeito da condução do programa, cabe destacar que, embora já tivesse realizado apresentação de programas radiofônicos (debates, mesas redondas etc.) em outras oportunidades, a emoção de fazêe-lo tratando assuntos da área nos alegra ainda mais. [...] A expectativa de podermos realizar outras ações desta natureza fortalece as relações institucionais, ampliando debates para outros segmentos sociais. (BRONOSKY, 2017).

Com trabalhos técnicos de Reinaldo dos Santos, o programa foi gravado no estúdio número um do Laboratório de Radiojornalismo no Campus Central da Universidade Estadual 
de Ponta Grossa, no dia 8 de novembro de 2016, entre 10 horas e 11h30, e foi transmitido pela Rádio USP no dia 18 de dezembro de 2016, às 11 horas.

\section{Considerações finais}

Uma das referências para a montagem dos programas foi a obra Gêneros radiofônicos os formatos e os programas em áudio, do pesquisador André Barbosa Filho (2003). O autor destaca o formato da Divulgação Tecnocientífica, que, assim, se aproxima da proposta aplicada aos três programas analisados: "Este formato tem a função de divulgar e, consequentemente, informar a sociedade sobre o mundo da ciência, com roteiros apropriados e linguagem que seja acessível à maioria da população" (p. 109).

Para facilitar o entendimento do ouvinte os programas foram planejados por meio de um diálogo entre os locutores (mediadores) e os autores. Logo, a base foi a entrevista, com a possibilidade de introduzir outras produções como depoimentos de colaboradores, reconstituições de trechos das obras, músicas, arquivos sonoros, produções dos responsáveis, entre outros. Esses produtos foram introduzidos com o objetivo de gerar quebras propositais à conversa, que contextualizariam as perguntas e, além disso, ilustrariam o programa.

Como os três programas eram Especiais do Universidade 93,7, seria possível fazer um trabalho diferenciado, por meio da pesquisa e da produção. A professora e pesquisadora da Universidade de São Paulo Gisela Swetlana Ortriwano (1948-2003) explica que o Especial necessita de um planejamento ainda mais elaborado do que os demais programas informativos: "Pressupõe pesquisa aprofundada sobre o tema, tanto no que diz respeito às informações textuais como às sonoras, principalmente as entrevistas" (ORTRIWANO, 1995, p. 92).

Uma das principais diferenças dos três programas transmitidos pela Rádio USP era a necessidade de um vínculo entre o entrevistador e o entrevistado. O locutor (mediador) precisava conhecer as obras do (a) autor (a), assim como ter alguma relação profissional com o (a) mesmo (a), justamente para facilitar o entendimento da pesquisa e, consequentemente, da obra por parte do ouvinte. Seguiram-se, assim, os parâmetros observados pelo professor e pesquisador da Universidade Federal do Rio Grande do Sul, Luiz Artur Ferraretto, a respeito do conceito sobre entrevista. Nas suas palavras:

\footnotetext{
A entrevista envolve um contato planejado com a pessoa caracterizada como fonte de informação. O profissional, portanto, prepara-se para tal e segue um roteiro de indagação com dose variável de improviso, dependendo do tempo disponível e da própria interação com o entrevistado e o assunto. Planejar uma entrevista significa pesquisar o tema e/ou a pessoa enfocada, estabelecendo um raciocínio a respeito que orienta o questionamento. (FERRARETTO, 2014, p. 179-180).
} 
O fato de serem ex-alunos, ex-professores ou mesmo colegas de trabalho permitiu a fluidez no diálogo, sem o aprisionamento das perguntas ao roteiro. Da mesma forma, a conversa ocorreu de maneira solta, beneficiando os entrevistados que, assim, tinham a oportunidade de contextualizar suas respostas.

A escolha de um formato híbrido, ou seja, o Especial de Divulgação Tecnocientífica, que teve como base a entrevista, foi fundamental para a construção dos programas, pois o principal objetivo era facilitar o entendimento do público diante dos assuntos oriundos de trabalhos acadêmicos. Outro objetivo alcançado foi trabalhar o radiojornalismo como ferramenta de divulgação científica. Da mesma forma, os casos analisados neste artigo possibilitaram uma relação ainda mais particular, por discutirem o próprio jornalismo, seus problemas e contribuições.

\section{Referências}

BARBOSA FILHO, André. Gêneros radiofônicos: os formatos e os programas em áudio. São Paulo: Paulinas, 2003.

BRONOSKY, Marcelo Engel. Depoimento concedido ao autor. Via Internet, 7 mar. 2017.

BUENO, Wilson da Costa. Jornalismo científico: revisitando o conceito. In: VICTOR, Cilene; CALDAS, Graça; BORTOLIERO, Simone (Orgs.). Jornalismo científico e desenvolvimento sustentável. São Paulo: All Print, 2009.

CARDOSO, Marcelo. Um jornalismo da empatia, dialogia e solidariedade. Revista Regit: Revista de Estudos de Gestão, Informação e Tecnologia da Faculdade de Tecnologia de Itaquaquecetuba,), v. 6, n. 2, p. 136-140, jul./dez. 2016. Disponível em: <http://fatecitaqua.edu.br/revista/index.php/regit>. Acesso em: 9 abr. 2017.

CARDOSO, Marcelo. Depoimento concedido ao autor. São Paulo, 6 mar. 2017.

FERRARETO, Luiz Artur. Rádio: teoria e prática. São Paulo: Summus, 2014.

GENRO FILHO, Adelmo. O segredo da pirâmide: para uma teoria marxista do jornalismo. São Paulo: Tchê, 1987. Disponível em: <http://www.adelmo.com.br/index1.htm>. Acesso em: 9 abr. 2017.

IJUIM, Jorge Kanehide. Cremilda Medina e o Ato Presencial. Revista Alterjor, São Paulo, v. 15, n.1, p. 187-191, jan./jun. 2017. Disponível em:

<http://revistas.usp.br/alterjor/article/view/127959>. Acesso em: 7 abr. 2017.

IJUIM, Jorge Kanehide. Depoimento concedido ao autor. Via Internet, 9 mar. 2017.

MEDINA, Cremilda Celeste de Araújo. Depoimento concedido ao autor. São Paulo, 7 mar. 2017.

MEDINA, Cremilda Celeste de Araújo. Ato presencial: mistério e transformação. São Paulo: Casa da Serra, 2016.

MEDINA, Cremilda Celeste de Araújo. A arte de tecer o presente: narrativa e cotidiano. São Paulo: Summus, 2003. 
MEDINA, Cremilda Celeste de Araújo. Notícia: um produto à venda. São Paulo: AlfaOmega, 1978.

ORTRIWANO, Gisela Swetlana. A informação no rádio: os grupos de poder e a determinação dos conteúdos. São Paulo: Summus, 1985.

PONTES, Felipe Simão. Adelmo Genro Filho e a teoria do jornalismo. Florianópolis: Insular, 2015.

PONTES, Felipe Simão. Adelmo Genro Filho e a teoria do jornalismo no Brasil: uma análise crítica. Tese (Doutorado em Sociologia Política) - Universidade Federal de Santa Catarina, Florianópolis, 2015.

PONTES, Felipe Simão. Depoimento concedido ao autor. Via Internet, 9 mar. 2017.

ROVIDA, Mara Ferreira. Depoimento concedido ao autor. Via Internet, 8 mar. 2017.

ROVIDA, Mara Ferreira. Jornalismo em trânsito: o diálogo social solidário no espaço urbano. São Paulo: EdUFSCar, 2015.

ROVIDA, Mara Ferreira. Jornalismo em trânsito: o diálogo social solidário no espaço urbano. Tese (Doutorado em Ciências da Comunicação) - ECA, Universidade de São Paulo, São Paulo, 2014.

XAVIER, Cintia. O jornalismo é "às vezes" uma forma de conhecimento. Revista Alterjor, São Paulo, v. 15, n. 1, p. 181-187, jan./jun. 2017. Disponível em:

<http://revistas.usp.br/alterjor/article/view/127957>. Acesso em: 6 abr. 2017.

Luciano Victor Barros Maluly - Escola de Comunicações e Artes da Universidade de São Paulo (ECA-USP) | CJE e PPGCOM | São Paulo | SP | Brasil. E-mail: lumaluly@usp.br 